\title{
Molecular cloning and expression analysis of Fem $1 b$ from oriental river prawn Macrobrachium nipponense
}

\author{
N.M.A. Rahman ${ }^{1,3}$, H. Fu ${ }^{1,2}$, H. Qiao ${ }^{2}$, S. Jin², H. Bai' ${ }^{1}$ W. Zhang ${ }^{2}$,

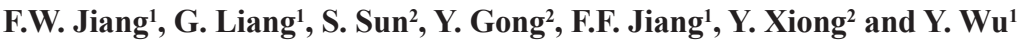 \\ ${ }^{1}$ Wuxi Fisheries College, Nanjing Agricultural University, Wuxi, China \\ ${ }^{2}$ Key Laboratory of Freshwater Fisheries and Germplasm Resources Utilization, \\ Ministry of Agriculture, Freshwater Fisheries Research Center, \\ Chinese Academy of Fishery Sciences, Wuxi, China \\ ${ }^{3}$ Fisheries Research Center, \\ Animal Research Corporation of the Ministry of Animal Resources, \\ Khartoum, Sudan \\ Corresponding author: $\mathrm{H}$. Fu \\ E-mail: fuht@ffrc.cn
}

Genet. Mol. Res. 15 (2): gmr.15027950

Received October 29, 2015

Accepted January 15, 2016

Published May 25, 2016

DOI http://dx.doi.org/10.4238/gmr.15027950

\begin{abstract}
Feminization-1 homolog b (Fem 1b) is one of the genes essential for male development and play central roles in sex determination of Caenorhabditis elegans. In this study, we cloned and characterized the full-length $F e m 1 b$ cDNA from the freshwater prawn Macrobrachium nipponense (MnFem 1b) in different tissues and at different developmental stages. Real-time quantitative reverse polymerase chain reaction (RT-qPCR) showed that the $M n F e m 1 b$ gene was expressed in all investigated tissues, with the highest expression level found in the testes. The results revealed that the MnFem $1 b$ gene might play roles in aspects of development of the male prawn phenotype. The RT-qPCR also revealed that MnFem $1 b$ mRNA expression was significantly increased at 10 days after metamorphosis. The expression
\end{abstract}


levels in all investigated tissues showed a certain degree of sexually dimorphism, the expression levels in males were significantly higher than those in females $(\mathrm{P}<0.05)$. Notably, the highest expression of $\mathrm{MnFem} 1 \mathrm{~b}$ was found in the testes. The expression of MnFem $1 b$ in different tissues indicates that it plays multiple biological functions in M. nipponense.

Key words: Macrobrachium nipponense; Expression pattern; Feminization-1 homolog b (Fem 1b); Crustacean; RT-qPCR; Post-larval

\section{INTRODUCTION}

The feminization-1 (Fem 1) gene is well known for its function as a signal transducing regulator affecting sex determination in the nematode Caenorhabditis elegans. The Fem 1 gene of $C$. elegans encodes an ankyrin (ANK) repeat protein that negatively regulates the transcription factor TRA-1, and functions as an E3 ubiquitin ligase substrate recognition subunit (SRS) to target TRA-1 for ubiquitylation (Doniach and Hodgkin, 1984; Spence et al., 1990; Hodgkin, 2002; Jäger et al., 2004; Starostina et al., 2007). Except in nematodes, the Fem 1 gene family, which consists of at least three members designated Fem 1a, Fem 1b, and Femlc, has also been identified in mammals. The other Feml gene family members show a high degree of evolutionary conservation with that of $C$. elegans, indicating that they may play similar roles (Chan et al., 2000; Ventura-Holman and Maher, 2000; Krakow et al., 2001; Ventura-Holman et al., 2003). Recently, Fem1 homologs have also been found in insects (Shi et al., 2013; Xiong et al., 2014) and crustaceans (Robinson et al., 2014; Song et al., 2015). This leads to a new line of questioning: whether the sex determination mechanism of arthropods is similar to that of nematodes. A single nucleotide polymorphism marker, occurring in a transcript of Feml, has been found to be significantly associated with sex in Penaeus monodon, whereas the expression profile of three crab Fem 1 genes (designated EsFem 1a, EsFem 1b, and EsFem 1c) indicated that they might function in crab early sex determination and late gonad development. Together, these results provide new insights into the crustacean sex-determining mechanism.

The oriental river prawn, Macrobrachium nipponense (Crustacea; Decapoda; Palaemonidae) is a commercial freshwater prawn. It is considered an important commercial species in aquaculture and a capture fishery resource in China (Fu et al., 2012), with a calculated capture of 251,000 tons in 2013 (Bureau of Fishery, 2014). Male oriental river prawns are believed to grow faster and achieve higher weights during harvest compared to females. Culturing of all-male populations may therefore be beneficial economically. Therefore, studies on sex-determination are of great importance to M. nipponense aquaculture. However, little information on sex-determination has been reported, and the sex-determination mechanism remains unclear in M. nipponense.

In the current study, we identify Fem $1 b$ homologs in the androgenic gland transcriptome (Jin et al., 2013) of $M$. nipponense. In addition, we report the full length of the cDNA sequence and amino acid characterization of the Fem $1 b$ gene of $M$. nipponense and analyze its structural characteristics. A phylogenetic tree was built, in order to establish $\mathrm{MnFem} 1 \mathrm{~b}$ orthology. Moreover, the expression levels of the MnFem lbgene in different adult tissues and 
developmental stages of embryos and larvae were determined, using real-time quantitative polymerase chain reaction (RT-qPCR). These results will provide a better understanding and directions for future research on the mechanisms of sex determination in M. nipponense.

\section{MATERIAL AND METHODS}

\section{Prawn and tissue preparation}

Adult M. nipponense with an average body weight of 2.3-4.5 g were obtained from Tai Lake in Wuxi, China (120 13 '44"E, $\left.31^{\circ} 28^{\prime} 22^{\prime \prime} \mathrm{N}\right)$. Different developmental stages and tissues of adult animals were used for total RNA extraction. Adult prawns were kept under laboratory breeding conditions at $23^{\circ} \mathrm{C}$ and acclimatized in a 500-L tank with aerated freshwater for $72 \mathrm{~h}$ before tissue collection. Embryos and larvae at different developmental stages were obtained from a breeding room. After prawn spawning, each embryonal developmental stage (cleavage stage, blastula stage, gastrula stage, five larval stages, and three post-larval stages) was collected and inspected using an Olympus SZX16 microscope. The samples were classified based on morphological characters, following the criteria of Chen et al. (2012). The ovary, testis, muscle, heart, androgenic gland, brain, eye stalk gill, and hepatopancreas were also collected from mature male and female prawns. The samples were washed with $1 \mathrm{X} 0.01$ $\mathrm{M}$ phosphate-buffered saline, frozen in liquid nitrogen, and stored at $-20^{\circ} \mathrm{C}$ until processed (Zhang et al., 2013; Jiang et al., 2015).

\section{RNA isolation and reverse transcription}

RNA was extracted from the different developmental stages and tissues fromat least three adult M. nipponense, using RNAiso plus kit (TaKaRa, Dalian, China) following the manufacturer protocol. The RNA was treated with RNase-free DNase I (Sangon, Shanghai, China), to remove any possible genomic DNA contamination. The quality and quantity of RNA were assessed by BioPhotometer (Eppendorf, Hamburg, Germany) at 260 and $280 \mathrm{~nm}$, respectively. To check the integrity of each sample, $2 \mu \mathrm{L}$ was analyzed on $1 \%$ agarose gel. The concentration of each RNA sample was adjusted to $1 \mathrm{mg} / \mu \mathrm{L}$ with nuclease-free water. Firststrand cDNA synthesis was performed, using $1 \mu \mathrm{L}$ total RNA, $4 \mu \mathrm{L} 5 \mathrm{X}$ iScript reaction mix (Bio-Rad, USA), and $1 \mu \mathrm{L}$ iScript reverse transcriptase to a final volume of $20 \mu \mathrm{L}$. Then, 15 $\mu \mathrm{L}$ water was added to reach a final volume of $20 \mu \mathrm{L}$. The reaction was incubated at $25^{\circ} \mathrm{C}$ for $5 \mathrm{~min}$, at $42^{\circ} \mathrm{C}$ for $30 \mathrm{~min}$, followed by $85^{\circ} \mathrm{C}$ for $5 \mathrm{~min}$. The reverse transcribed cDNA was stored at $-20^{\circ} \mathrm{C}$ until the RT-qPCR.

\section{Rapid amplification of cDNA ends (RACE)}

Based on the DNA sequence data obtained from the androgenic gland transcriptome search (Jin et al., 2013) (http://www.ffrc.cn/gene/list.asp), a pair of gene-specific primers were designed and synthesized to clone the full-length cDNA of $M n F e m l b$ by rapid amplification of cDNA ends (RACE), using testis RNA as a template. All primers used in RACE are presented in Table 1. Cloning the full-length $M n F e m 1 b$ cDNA sequence was performed using a 5' and 3' RACE cDNA Amplification Kit (TaKaRa) according to the manufacturer protocol. 
The MnFem $1 b$ cDNA sequences were extended using 5'/3' RACE. The PCR products were subjected to electrophoresis on $1.5 \%$ agarose gels, to compare differences in product length. The DNA bands of the expected size were excised from the agarose gel and purified using a DNA gel extraction kit (Axygen, Union City, CA, USA). Amplified cDNA fragments were cloned in the pMD18-T vector (TaKaRa) and sequenced with M13 forward and reverse primers. Subsequently, at least five independent clones were sequenced from each cDNA and the sequences were verified and subjected to cluster analysis in NCBI (http:/www.ncbi.nlm. nih.gov/).

Table 1. Nucleotide sequences of primers used for $\mathrm{MnFem} 1 \mathrm{~b}$ cloning and expression analysis.

\begin{tabular}{|c|c|c|}
\hline & Sequence $\left(5^{\prime} \rightarrow 3^{\prime}\right)$ & Code \\
\hline \multicolumn{3}{|l|}{ Primers for 5'RACE PCR } \\
\hline MnFemlb 5' GSP primer 1 & TCCTGATTTCGCTTCAGTTCCA & GSP1 \\
\hline MnFem $1 \mathrm{~b} 5^{\prime}$ GSP primer 2 & ACATCTGTCGAACCTGGCATTA & GSP2 \\
\hline \multicolumn{3}{|l|}{ Primers for 3'RACE PCR } \\
\hline MnFem1b 3' GSP primer 1 & GGTAAGAGTGCAACCGAGAACTA & GSP3 \\
\hline MnFem 1b 3' GSP primer 2 & TCAAGTTCCGTATCACCTGGAAG & GSP4 \\
\hline \multicolumn{3}{|l|}{ Full RACE ${ }^{\mathrm{TM}}$ Kit primers } \\
\hline 3' RACE OUT & ATCCGACGAAGACAAACTCTACC & \\
\hline 3' RACE IN & CGCGGATCCTCCACTAGTGATTTCACTATAGG & \\
\hline 5' RACE OUT & CTCCACAATGGGCTTTTTCATCC & \\
\hline 5' RACE IN & CGCGGATCCACAGCCTACTGATGATCAGTCGATG & \\
\hline \multicolumn{3}{|c|}{ Primers for real-time PCR analysis } \\
\hline MnFem1b 5' primer & CTCCACAATGGGCTTTTTCATCC & RT-F1 \\
\hline MnFemlb 3' primer & ATCCGACGAAGACAAACTCTACC & RT-R1 \\
\hline$\beta$-actin 5' primer & TATGCACTTCCTCATGCCATC & actinF \\
\hline$\beta$-actin 3' primer & AGGAGGCGGCAGTGGTCAT & actinR \\
\hline
\end{tabular}

\section{Nucleotide sequence and bioinformatic analyses}

Based on the BLASTx algorithm (http:/www.ncbi.nlm.nih.gov/BLAST/), the $M n F e m 1 b$ sequence from the AG transcriptome of $M$. nipponense was found to be highly homologous to the Chinese mitten crab Eriocheir sinensis Fem1b (EsFem1b) gene family. The 5' and 3' sequences from the RACE were assembled with the fractional cDNA sequence homologous to each fragmental sequence using DNAMAN 5.0. Sequences were analyzed, based on the nucleotide and protein databases using the BLASTx and BLASTn programs (http:/www.ncbi.nlm.nih.gov/BLAST/). Protein prediction was performed using ORF finder (http://www.ncbi.nlm.nih.gov/gorf/). The ProtParam program (http://www. expasy.ch/tools/protparam.html) was used to compute physical and chemical parameters of the amino acid sequence. The motif was searched using the motif scan program (http:// myhits.isb-sib.ch/cgi-bin/motif_scan/). The functional domain analysis was performed using SMART GENOMES (http://smart.embl.de/smart/set_mode.cgi?GENOMIC=1). To predict the signal peptide, SignalP 4.1 Server was used (http://www.cbs.dtu.dk/services/ SignalP/). Multiples of Fem 1 homologue b (Table 2) were formed using DNAMAN 5.0. Based on the amino acid sequences, a phylogenetic tree was constructed by means of a neighbor-joining method. The bootstrapping test was performed using 1000 replications with MEGA4 (Tamura et al., 2007). 


\begin{tabular}{|c|c|c|c|}
\hline Species & Molecular name/accession number & Order/family & Identity $\%$ \\
\hline \multirow[t]{3}{*}{ Homo sapiens } & Fem-1a/AAH04988 & \multirow[t]{3}{*}{ Primates/Hominidae } & 29 \\
\hline & Fem-1b/AAH14558Fem-1c/AAH28369 & & 51 \\
\hline & & & 43 \\
\hline \multirow[t]{3}{*}{ Mus musculus } & Fem-1a/AAC82372 & \multirow[t]{3}{*}{ Rodentia/Muridae } & 30 \\
\hline & Fem-1b/AAC82373 & & 51 \\
\hline & Fem-1c/NP_775599 & & 35 \\
\hline \multirow[t]{3}{*}{ Locusts migratoria manilensis } & Fem-1a/BAL61211 & \multirow[t]{3}{*}{ Orthoptera/Acrididae } & 25 \\
\hline & Fem-1b/BAL61212 & & 65 \\
\hline & Fem-1c/BAL61213 & & 32 \\
\hline Litopenaeus vannamei & Fem-1/AHA90856 & Decapoda/Penaeidae & 32.66 \\
\hline \multirow[t]{3}{*}{ Eriocheir sinensis } & Fem-1a/KR108010 & \multirow[t]{3}{*}{ Decapoda/Varunidae } & 53 \\
\hline & Fem-1b/KR108011 & & 81 \\
\hline & Fem-1c/KR108012 & & 55 \\
\hline \multirow[t]{2}{*}{ Zootermopsis nevadensis } & Fem-1a/KDR09672.1 & \multirow[t]{2}{*}{ Isoptera/Termopsidae } & 25 \\
\hline & Fem-1b/KDR11581 & & 66 \\
\hline \multirow[t]{2}{*}{ Drosophila melanogaster } & Fem-1a/AAF57431 & \multirow[t]{2}{*}{ Diptera/Drosophilidae } & 40 \\
\hline & Fem-1b/AAM68397 & & 43 \\
\hline Macrobrachium nipponense & Fem-1a/ KT258023 & Decapoda/Palaemonidae & 100 \\
\hline
\end{tabular}

The table shows the identity percentage between different species Fem $1 a, b$, and $c$ and MnFemlb.

\section{Real-time quantitative PCR analysis of Fem $1 b$}

The transcriptional levels of the MnFem $1 b$ gene from the embryonal to post-larval stages and various adult tissues were measured using the SYBR Green RT-qPCR analysis using a Bio-Rad iCycler iQ5 Real Time System (Bio-Rad). The MnFem $1 b$ and $\beta$-actin primers are listed in (Table 1) were used to amplify the MnFem $1 b$ transcript, and the PCR products were sequenced, to verify the specificity of the PCR primers. From each developmental stage and each tissue, three samples were collected. Each sample was analyzed in triplicate. Each PCR well contained $25 \mu \mathrm{L}$ PCR mixture composed of $1 \mu \mathrm{L}$ cDNA (50 ng), $10 \mu \mathrm{L}$ SsoFast $^{\mathrm{TM}}$ EvaGreen $^{\circledR}$ Supermix (Bio-Rad), $0.5 \mu \mathrm{L} 10 \mu \mathrm{M}$ gene-speciðc forward and reverse primers (Table 1), and $13 \mu \mathrm{L}$ diethylpyrocarbonate-water (DEPC-water). The reaction mixture was initially incubated for $30 \mathrm{~s}$ at $95^{\circ} \mathrm{C}$ to activate the Hot Start Taq DNA polymerase, followed by 40 cycles of $10 \mathrm{~s}$ denaturation at $95^{\circ} \mathrm{C}$ and a $10 \mathrm{~s}$ extension at $60^{\circ} \mathrm{C}$. The melting curve analysis was performed over a range of $65-95^{\circ} \mathrm{C}$ (in $0.5^{\circ} \mathrm{C}$ increments) for $10 \mathrm{~s}$, to verify the generation of a single product. Amplification of $\beta$-actin (Zhang et al., 2013) as an internal reference was also carried out in the same sample (primer sequences are shown in Table 1). As a negative control, DEPC-water replaced the template. The relative copy number of MnFem $1 b$ mRNA was calculated according to the $2^{-\Delta \Delta C T}$ comparative CT method (Livak and Schmittgen, 2001).

\section{Statistical analysis}

Data were statistically analyzed using SPSS v. 19 (SPSS, Chicago, IL, USA) by one-way analysis of variances (ANOVA) followed by LSD multiple comparisons. Significant differences among the group means were further compared using Duncan's multiple range tests. $\mathrm{P} \leq 0.05$ was considered statistically significant. Results are reported as means $\pm \mathrm{SE}(\mathrm{N}=3)$.

\section{RESULTS}

\section{Sequence analysis of $\mathrm{MnFem} 1 \mathrm{~b}$}

The full-length cDNA sequence of MnFem $1 b$ was $2596 \mathrm{bp}$, and contained an open 
reading frame of $2055 \mathrm{bp}$, encoding a 684-amino acid protein. The protein had an estimated molecular mass of $75.6638 \mathrm{kDa}$, an isoelectric point of 6.74 with an untranslated region of $183 \mathrm{bp}$ the $5^{\prime}$ end, a $3^{\prime}$-untranslated region of $358 \mathrm{bp}$, and a complete poly A tail. The A+T and $\mathrm{C}+\mathrm{G}$ contents in the sequence were 53.8 and $46.2 \%$, respectively. This cDNA sequence was submitted to GenBank under accession No. KT258023. According to the blastx analysis, the sequence showed significant homology with the E. sinensis EsFem $1 a, b$, and $c$ genes with an identity of 53,81 , and $55 \%$, respectively. The conserved sequences and characteristic motifs of the chromatin organization modifier domain and N-terminal RGD, were identified in the deduced amino acid sequences of MnFem $1 b$. The conserved motifs were located in the Nand C-terminal region, respectively (Figure 1A-B). The region with highest identity between $M n F e m 1 b$ and EsFem $1 b$ was the N-terminal third of the amino acid sequences, which were composed of six continuous ANK repeats (Figure 1A).

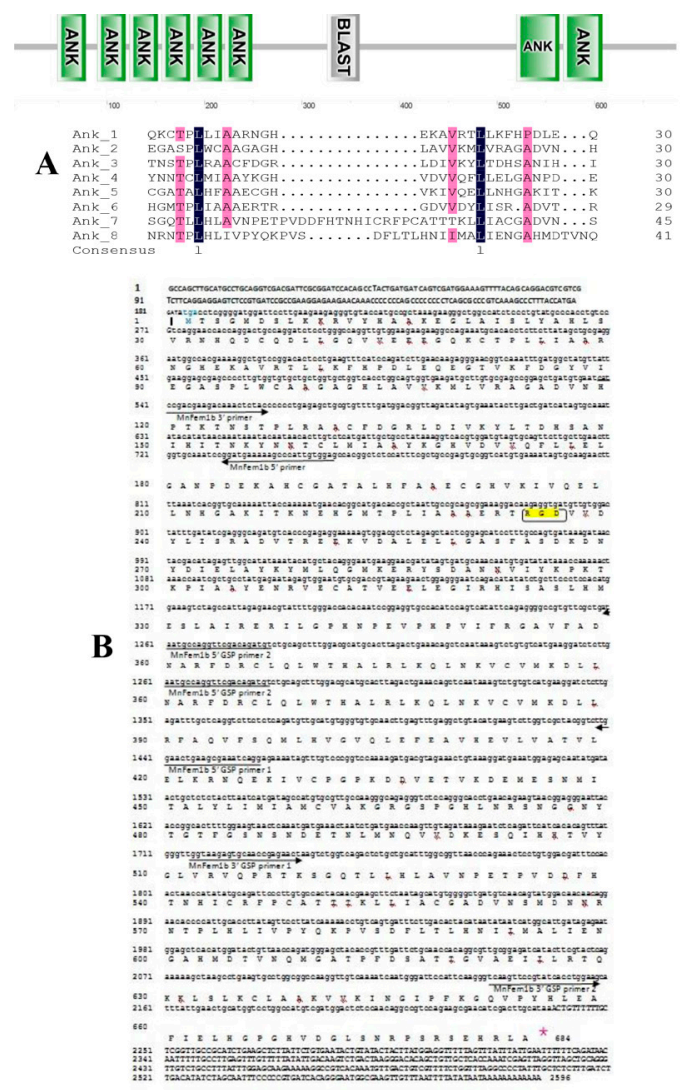

Figure 1. A. Domain analysis of Femlb amino acid sequences in Macrobrachium nipponense. The SMART analysis of $\mathrm{MnFem} 1 \mathrm{~b}$ and the sequence alignment of eight ANK repeats. The boxes represent the ANK structural elements. Identical and similar residues are highlighted in black and pink, respectively. B. Nucleotide and deduced amino acid sequence of MnFem $1 b$. The nucleotide sequence is displayed in the 5' to 3 ' direction and numbered at the left. The deduced amino acid sequence is shown in a single small letter amino acid code. The 3'- and 5'UTR are shown in capital letters. The codons are numbered at the left with the methionine (ATG) initiation codon (highlighted in blue text); an asterisk denotes the termination codon (TAA). The RACE and RT-qPCR primers are marked with arrows. RGD is highlighted in yellow. 
The signal peptide analysis identified no signal peptides in the amino acid sequence of $M n F e m 1 b$. The subcellular localization analysis revealed that the location of the predicted protein was in the cytoplasm. The amino acid sequence of $M n F e m 1 b$, when analyzed by functional domain, had eight ANK repeats, which consisted of approximately33 amino acids (Figure 1A). Compared with EsFem 1b, which has nine ANK repeats, MnFem 1 bhas eight ANK repeats, six of which are located at the N-terminal in both $M n F e m 1 b$ and EsFem $1 b$.

ExPASy were used to determine the protein functional sites in $M n F e m 1 b$. The mature protein was composed of three $\mathrm{N}$-glycosylation sites, one cAMP-and cGMP-dependent protein kinase sites, 13casein kinase II phosphorylation sites, eight N-myristoylation sites, 10 protein kinase $\mathrm{C}$ phosphorylation sites, one cell attachment sequence (RGD) and one tyrosine kinase phosphorylation site (Table 3).

Table 3. Functional site analysis of mature $M n F e m 1 b$ protein.

\begin{tabular}{l|l}
\hline Function site & AA position \\
\hline N-glycosylation site & $157-160$ (NNTC), 472-475 (NRSN), 478-481 (NYTG) \\
\hline cAMP- and cGMP-dependent protein kinase phosphorylation site & $630-633$ (KKLS) \\
\hline Casein kinase II phosphorylation site & 3 -6 (SGMD), 217-220 (TKNE), 233-236 (TRGD), 243-246 (SRAD), 248-251 (TREE), 265- \\
& 268(SDKD),313-316(TVEE),417-420(TVLE),439-442(TVKD), 487-490(SNDE),533- \\
\hline N-myristoylation site & 536(TPVD),612-615(TPFD), 677-680 (SRSE) \\
& $19-24$ (GLAISL), 114-119 (GADVNH), 213-218 (GSKITK), 260-265 (GASFAS), 354-359 \\
& (GAVFAD), 476-481 (GGNYTG), 484-489 (GSNSND), 559-564 (GADVNS) \\
\hline Protein Kinase C- phosphorylation site & $7-9$ (SLK), 29-31 (SVK), 81-83 (TVK), 153-155 (TNK), 265-267 (SDK), 439-441 (TVK), \\
\hline Cell attachment sequence & $551-553$ (TTK), 628-630 (TQK), 633-635 (SLK), 673-675 (SNR) \\
\hline Tyrosine kinase phosphorylation site & $234-236$ (RGD) \\
\hline
\end{tabular}

\section{Homology and phylogenetic analysis of MnFem 1b}

The MnFem 1 bamino acid sequence was compared with the sequences of previously described Fem $1 b$ proteins (Figure 2). The MnFem $1 b$ protein shared high identity with other species, including Zootermopsis nevadensis (KDR19644.1) 66\% and Locusta migratoria manilensis (BAL61212.1) 65\%. However, MnFemlb showed the highest homologywith another crustacean, E. sinensis (KR108011) EsFem 1b, with an identity of $81 \%$ (Table 2). The neighbor-joining phylogenetic tree of MnFem $1 b$ was constructed based on Fem 1a, b, and $c$ homologs from other species, using the MEGA 4.0 software (Figure 3) tree included Fem gene from crustaceans and other species. The species included in the phylogenetic tree are summarized in Table 2.

\section{Tissue distribution of MnFem $1 b$ mRNA}

The expression patterns of $M n F e m l b$ in the testis, ovary, heart, hepatopancreas, brain, muscle, eyestalk, gill, and androgenic gland tissues were examined. The RT-qPCR analysis of $M n F e m 1 b$ mRNA indicated that it was expressed in all examined tissues in the adult prawns, with the highest expression in the testis, followed by the hepatopancreas. The lowest levels were detected in the muscle tissue (Figure 4). In addition, we observed sexually dimorphic expression of $\mathrm{MnFem} 1 \mathrm{~b}$; the mRNA expression was higher in male compared to in female tissues ( $\mathrm{P}<0.05$; Figure 4). 


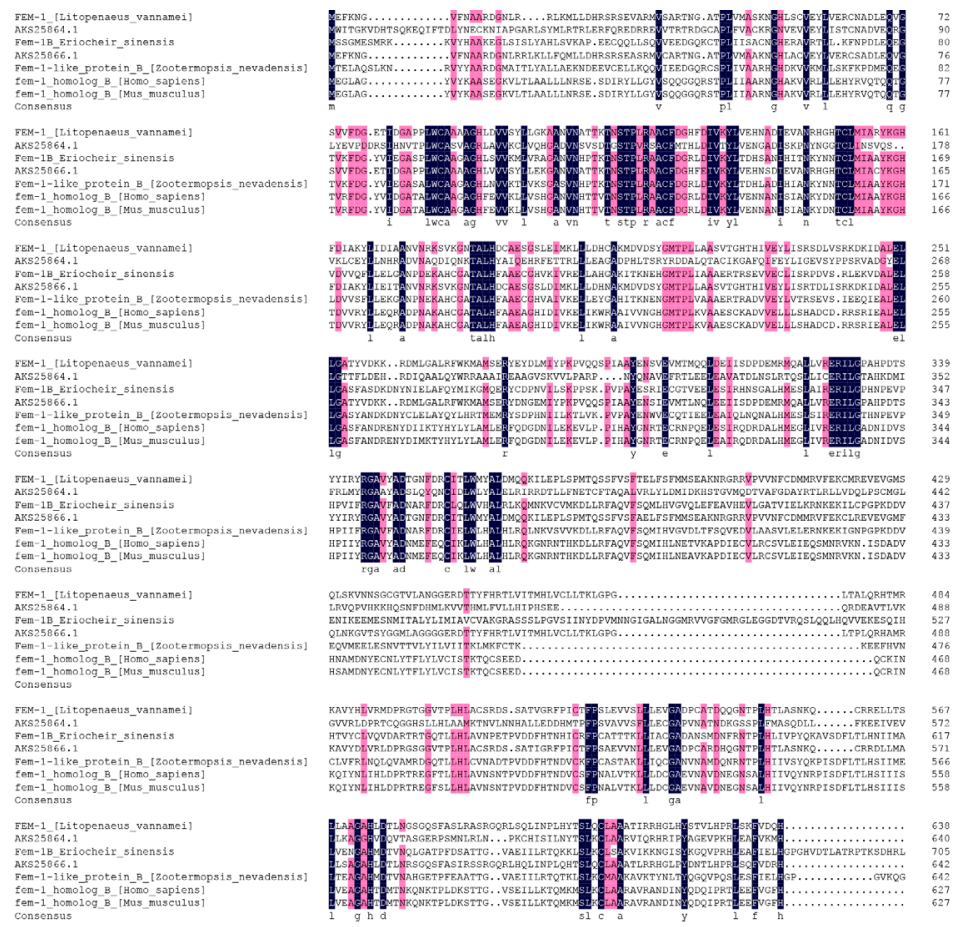

Figure 2. Multiple alignments of Macrobrachium nipponense Fem 1 lb sequence with that of other species, using DNAMAN. The deduced amino acid sequences are summarized in Table 2. Identical amino acid residues are highlighted in black and similar amino acids are highlighted in pink. Dotted inserts are added to maximize sequence identity.

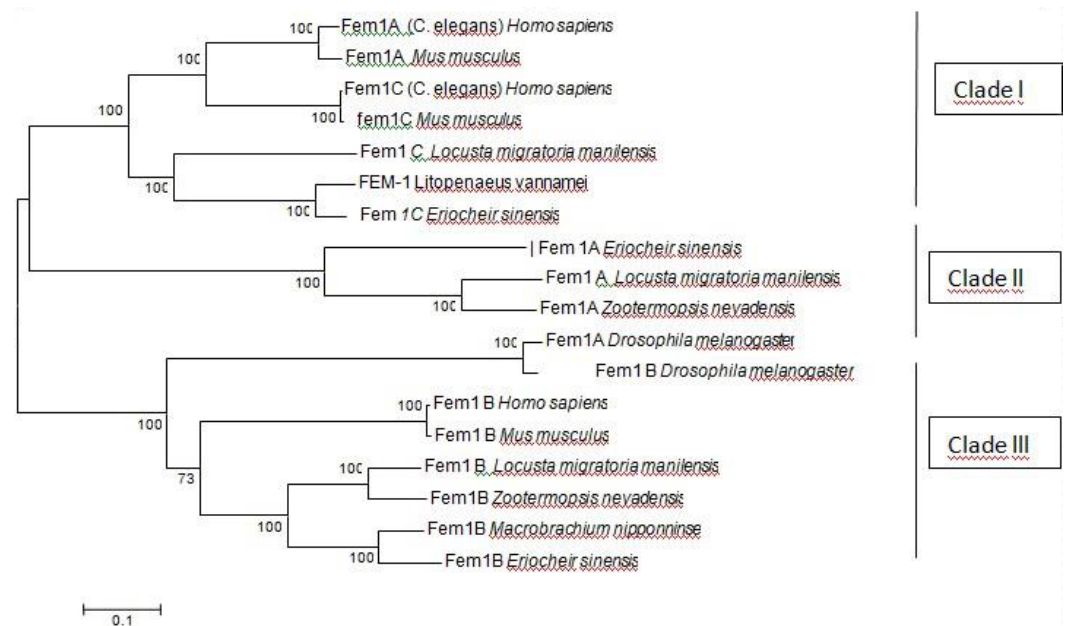

Figure 3. Neighbor-joining phylogenetic tree of MnFem 1 band Fem $1 b$ homologs. The species used in the phylogenetic tree are summarized in Table 2. Bootstrap analysis of 1000 replicates was carried out to determine the confidence of tree node positions. The numbers indicated at the tree nodes represent the bootstrap values. Numbers in the branches represented the bootstrap values (\%) from100 replicates. 


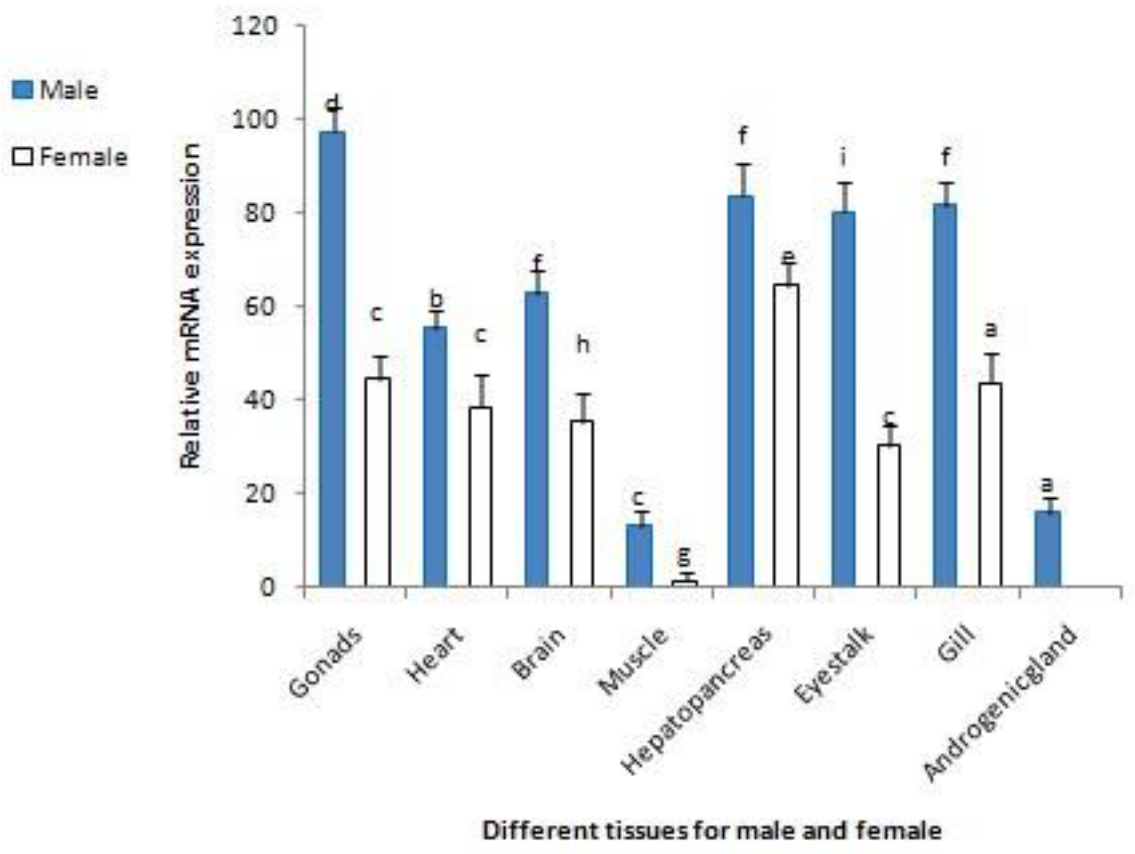

Figure 4. Distribution of Fem $1 b$ mRNA in different tissues of male and female prawns. Data are reported as the mean fold change (means \pm standard error of the mean, $N=3$ ). Statistical significance was calculated by one-way analysis of variance followed by multiple comparison tests. Bars with different letters were significant at $\mathrm{P}<0.05$. Gonads: testis and ovary.

\section{Expression analysis of MnFem $1 b$ mRNA during embryo, larvae, and post-larval stages}

MnFem $1 b$ mRNA expression levels were examined using RT-qPCR on M. nipponense embryos at different developmental stages, including both larval and post-larval stages. The results revealed that the $M n F e m 1 b$ gene was expressed at all developmental stages. The expression level increased gradually from the cleavage stage to the gastrula stage, it abruptly decreased during the pre-nauplius stage, and then increased again during the pre-zoea stage. This was followed by a gradual decrease until the expression reached its lowest level at day 10 of the larval stage. After metamorphosis, the expression of MnFem $1 b$ mRNA abruptly increased with increasing number of days after metamorphosis peaking at day 10 of the postlarval stage (Figure 5). Subsequently, expression both increases and decreases throughout the larval phases.

\section{DISCUSSION}

ANK repeats are composed of several modules of approximately 33 amino acids. It is one of the most common protein-protein interaction motifs, functioning directly or indirectly in signal transduction, transcriptional regulation, and developmental regulation (Lambert et al., 1990; Bork, 1993; Batchelor et al., 1998; Baumgartner et al., 1998; Li et al., 2009). They 


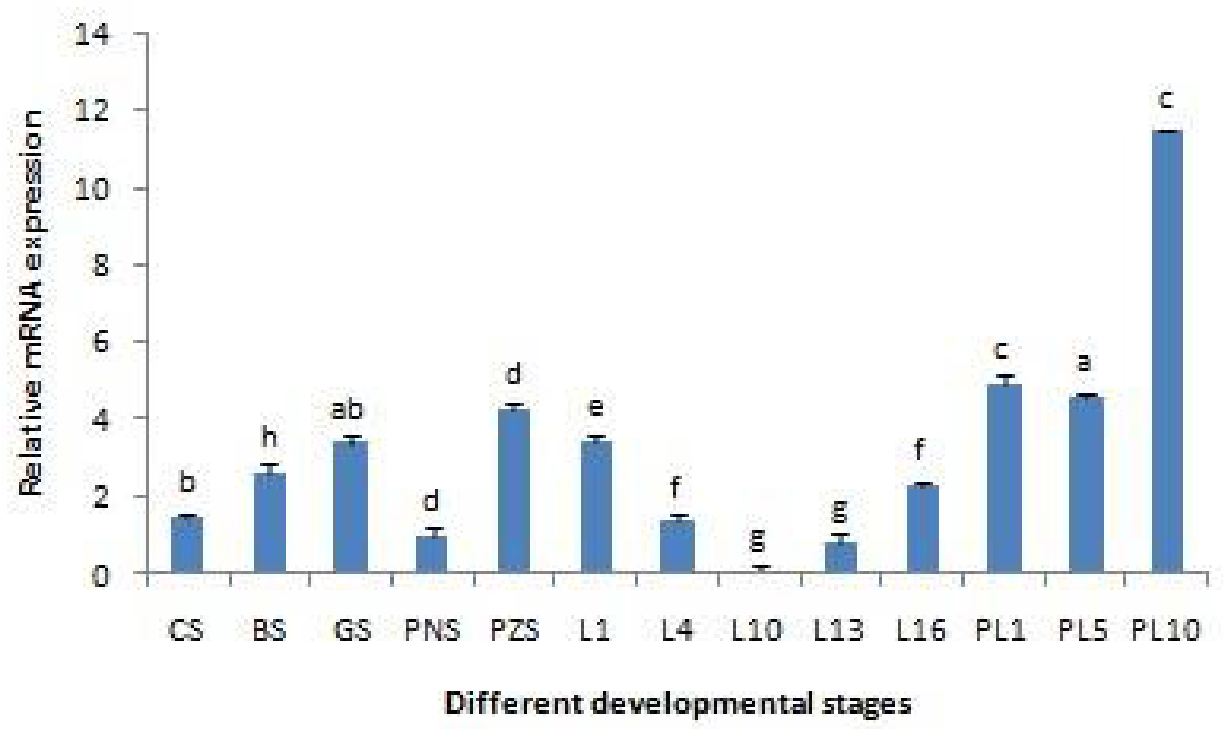

Figure 5. Temporal expression of MnFem $1 b$ during different developmental stages. Data are reported as means \pm standard error of the three repeated samples during the embryo, larva, and post-larva stages. Bars with different letters were significant at $\mathrm{P}<0.05$. $\mathrm{CS}=$ cleavage stage; $\mathrm{BS}=$ blastula stage; $\mathrm{GS}=$ gastrula stage; $\mathrm{PNS}=$ prenauplius stage; $\mathrm{PZS}=$ pre-zoea stage; $\mathrm{L} 1$ = first day larva after hatching; $\mathrm{LX}=$ larval day $\mathrm{X}$ after hatching; $\mathrm{P} 1=$ first day post-larva after metamorphosis; PLX = post-larval day $\mathrm{X}$ after metamorphosis.

are highly conserved among diverse organisms, and the number of repeats ranges from seven to nine in Fem1. In C. elegans, seven ANK repeats were identified (Spence et al., 1990), whereas nine repeats were found in the freshwater pearl mussel Hyriopsis schlegelii (Xiong et al., 2014). For different members of $F e m 1$ ( $a, b$, and $c$ ), the number of ANK repeats vary. Nine, eight, and nine ANK repeats have been detected in mouse and human Fem 1a, Fem 1b, and Fem 1c, respectively (Ventura-Holman et al., 1998, 2003), and eight repeats were found in locust Feml (a, b, and c) (Shi et al., 2013). In the mitten crab, the Femla, Fem1b, and Femlc amino acid sequences have eight, nine, and eight repeats, respectively (Song et al.,

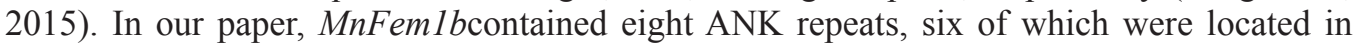
the N-terminal. The difference in Fem $1 b$ between prawns and other species might imply an evolutionary conservation and functional variation involved in nematode sex determination.

A neighbor-joining phylogenetic tree was constructed, based on the amino acid sequences of Fem 1 from various species. It indicated that individual members of the Fem 1 family were strongly conserved in the evolution across lineages. All Fem $1 b$ were clustered into one clade. MnFem $1 b$ clustered with the crabs Fem $1 b$ which indicated the highest closer relationship than fem $1 \mathrm{~b}$ from other species. The phylogenetic analysis revealed that the strong and stable conservation of the Fem 1 family was not simply based on a general ANK repeat consensus, but also on the sequence of the whole amino acid sequence.

The tissue distribution profile illustrated that the $\mathrm{MnFem} 1 \mathrm{~b}$ gene was expressed across several tissues, which indicates that it might have various functions in different tissues. The tissue expression profile of $M n F e m 1 b$ was similar to that found in human and Chinese mitten crab, displaying a high expression level in testis (Chan et al., 1999; Song et al., 2015). In 
contrast, it showed some differences with the expression level patterns found in mouse, in which the highest expression levels were found in the heart and skeletal muscle (VenturaHolman et al., 1998). MnFem 1 balso showed a certain degree of sexually dimorphic expression with the expression level in males being significantly higher than in females $(\mathrm{P}<0.05)$. Notably, MnFem $1 b$ showed the highest level of expression in the M. nipponense testis, which was also found in EsFemlb in crabs, indicating their potential role in aspects of the male phenotype (Song et al., 2015).

In the current study, MnFem $1 b$ mRNA was expressed differently during different developmental stages of $M$. nipponense. The expression level gradually increased with embryonic development from the cleavage to the gastrula stage followed by a significant decrease in the pre-nauplius stage. It then reached a peak expression level in the pre-zoea stage. The blastula and gastrula stages are two key stages of cell differentiation and organ formation (Zhang et al., 2010). The embryonic development expression results indicate that the functions of MnFem Ib were lasting and complex and might be involved in the sex determination. Our results are different from the results found in crabs and C. elegans, in which the authors inferred that the Fem 1 of both species were maternal genes that might help protect the identity and integrity of the germ line (Johnson and Spence, 2011; Song et al., 2015). Therefore, we speculate that $M n F e m 1 b$ may have other important roles during the embryonic development and organogenesis of M. nipponense. After hatching, the M. nipponense larvae need to undergo changes in morphology and appendage characteristics. During this time, the expression of MnFem $1 b$ remained at a low level, increasing markedly just after the metamorphosis. This suggests that MnFem 1 bplaysa certain role in the metamorphosis and morphological differentiation (Unni et al. 2003; Burghardt et al. 2005). In our previous study (Zhang et al., 2015), we found that primordial germ cells in M. nipponense appeared at 10-15 days post-larvae with external sexual forms occurring at 5-10 days post-larvae. The patterns of $M n F e m 1 b$ expression in post-larvae tended to coincide with the occurrence of primordial germ cells (PGCs) and external sexual forms of M. nipponense, suggesting that MnFem 1 bis involved in sex differentiation in $M$. nipponense.

In conclusion, we cloned the full length novel gene MnFem $1 \mathrm{~b}$ and investigated its transcriptional patterns in different tissues and development stages in M.nipponense. Important roles of MnFem $1 \mathrm{~b}$ may be found in the embryonic development and in post-larval external sexual formation of M. nipponense. From this study, we can infer that MnFem $1 b$ might have multiple biological roles. Further detailed investigations should be carried out to elucidate the specific functions of $\mathrm{MnFem} 1 \mathrm{~b}$.

\section{Conflicts of interest}

The authors declare no conflict of interest.

\section{ACKNOWLEDGMENTS}

Research supported by the National Natural Science Foundation of China (Grant \#31572617), the National Science \& Technology Supporting Program of the 12th Fiveyear Plan of China (\#2012BAD26B04), the Fund of Independent Innovation of Agricultural Sciences of Jiangsu province (CX (15)\#1012-4), the three aquatic projects of Jiangsu Province (\#D2015-16), and the Wuxi Science and Technology Development Fund (\#CLE02N1514). 


\section{REFERENCES}

Batchelor AH, Piper DE, de la Brousse FC, McKnight SL, et al. (1998). The structure of GABPalpha/beta: an ETS domainankyrin repeat heterodimer bound to DNA. Science 279: 1037-1041. http://dx.doi.org/10.1126/science.279.5353.1037

Baumgartner R, Fernandez-Catalan C, Winoto A, Huber R, et al. (1998). Structure of human cyclin-dependent kinase inhibitor p19INK4d: comparison to known ankyrin-repeat-containing structures and implications for the dysfunction of tumor suppressor p16INK4a. Structure 6: 1279-1290. http://dx.doi.org/10.1016/S0969-2126(98)00128-2

Bork P (1993). Hundreds of ankyrin-like repeats in functionally diverse proteins: mobile modules that cross phyla horizontally? Proteins 17: 363-374. http://dx.doi.org/10.1002/prot.340170405

Bureau of Fishery Ministry of Agriculture, P.R.C. (2014). Fisheries economic statistics. In: China Fishery Yearbook. China Agricultural Press, Beijing.

Burghardt G, Hediger M, Siegenthaler C, Moser M, et al. (2005). The transformer2 gene in Musca domestica is required for selecting and maintaining the female pathway of development. Dev. Genes Evol. 215: 165-176. http://dx.doi. org/10.1007/s00427-004-0464-7

Chan SL, Tan KO, Zhang L, Yee KS, et al. (1999). F1Aalpha, a death receptor-binding protein homologous to the Caenorhabditis elegans sex-determining protein, FEM-1, is a caspase substrate that mediates apoptosis. J. Biol. Chem. 274: 32461-32468. http://dx.doi.org/10.1074/jbc.274.45.32461

Chan SL, Yee KS, Tan KM and Yu VC (2000). The Caenorhabditis elegans sex determination protein FEM-1 is a CED-3 substrate that associates with CED-4 and mediates apoptosis in mammalian cells. J. Biol. Chem. 275: 17925-17928. http://dx.doi.org/10.1074/jbc.C000146200

Chen Y, Zhu Q, Chen H, Zhu X, et al. (2012). The morphological and histological observation of embryonic development in the oriental river prawn Macrobrachium nipponense. J. Shanghai Ocean Univ. 21: 33-40.

Doniach T and Hodgkin J (1984). A sex-determining gene, fem-1, required for both male and hermaphrodite development in Caenorhabditis elegans. Dev. Biol. 106: 223-235. http://dx.doi.org/10.1016/0012-1606(84)90077-0

Fu H, Jiang S and Xiong Y (2012). Current status and prospects of farming the giant river prawn (Macrobrachium rosenbergii) and the oriental river prawn (Macrobrachium nipponense) in China. Aquacult. Res. 43: 993-998. http:// dx.doi.org/10.1111/j.1365-2109.2011.03085.x

Hodgkin J (2002). Exploring the envelope. Systematic alteration in the sex-determination system of the nematode caenorhabditis elegans. Genetics 162: 767-780.

Jäger S, Schwartz HT, Horvitz HR and Conradt B (2004). The Caenorhabditis elegans F-box protein SEL-10 promotes female development and may target FEM-1 and FEM-3 for degradation by the proteasome. Proc. Natl. Acad. Sci. USA 101: 12549-12554. http://dx.doi.org/10.1073/pnas.0405087101

Jiang SF, Zhang YP, Sun SM, Gong YS, et al. (2015). Molecular cloning, characterization, and expression analysis of a Broad-Complex homolog during development in the oriental river prawn Macrobrachium nipponense. Genet. Mol. Res. 14: 5141-5152. http://dx.doi.org/10.4238/2015.May.18.4

Jin S, Fu H, Zhou Q, Sun S, et al. (2013). Transcriptome analysis of androgenic gland for discovery of novel genes from the oriental river prawn, Macrobrachium nipponense, using Illumina Hiseq 2000. PLoS One 8: e76840. http://dx.doi. org/10.1371/journal.pone.0076840

Johnson CL and Spence AM (2011). Epigenetic licensing of germline gene expression by maternal RNA in C. elegans. Science 333: 1311-1314. http://dx.doi.org/10.1126/science.1208178

Krakow D, Sebald E, King LM and Cohn DH (2001). Identification of human FEM1A, the ortholog of a C. elegans sexdifferentiation gene. Gene 279: 213-219. http://dx.doi.org/10.1016/S0378-1119(01)00756-9

Lambert S, Yu H, Prchal JT, Lawler J, et al. (1990). cDNA sequence for human erythrocyte ankyrin. Proc. Natl. Acad. Sci. USA 87: 1730-1734. http://dx.doi.org/10.1073/pnas.87.5.1730

Li P, Zha J, Huang H, Zhang Z, et al. (2009). Identification, mRNA expression and characterization of a novel ANK-like gene from Chinese mitten crab Eriocheir japonica sinensis. Comp. Biochem. Physiol. B Biochem. Mol. Biol. 153: 332-339. http://dx.doi.org/10.1016/j.cbpb.2009.04.005

Livak KJ and Schmittgen TD (2001). Analysis of relative gene expression data using real-time quantitative PCR and the $\left.2^{(-\Delta \Delta \mathrm{C}(\mathrm{T})}\right)$ Method. Methods 25: 402-408. http://dx.doi.org/10.1006/meth.2001.1262

Robinson NA, Gopikrishna G, Baranski M, Katneni VK, et al. (2014). QTL for white spot syndrome virus resistance and the sex-determining locus in the Indian black tiger shrimp (Penaeus monodon). BMC Genomics 15: 731. http:// dx.doi.org/10.1186/1471-2164-15-731

Shi H, Hao YJ, Chen B, Si FL, et al. (2013). Cloning and expression analysis of fem-1 genes from the oriental migratory locust, Locusta migratoria manilensis (Orthoptera: Locustidae). Acta Entomol. Sin. 56: 729-737.

Song C, Cui Z, Hui M, Liu Y, et al. (2015). Molecular characterization and expression profile of three Fem-1 genes in 
Eriocheir sinensis provide a new insight into crab sex-determining mechanism. Comp. Biochem. Physiol. B Biochem. Mol. Biol. 189: 6-14. http://dx.doi.org/10.1016/j.cbpb.2015.07.003

Spence AM, Coulson A and Hodgkin J (1990). The product of fem-1, a nematode sex-determining gene, contains a motif found in cell cycle control proteins and receptors for cell-cell interactions. Cell 60: 981-990. http://dx.doi. org/10.1016/0092-8674(90)90346-G

Starostina NG, Lim JM, Schvarzstein M, Wells L, et al. (2007). A CUL-2 ubiquitin ligase containing three FEM proteins degrades TRA-1 to regulate C. elegans sex determination. Dev. Cell 13: 127-139. http://dx.doi.org/10.1016/j. devcel.2007.05.008

Tamura K, Dudley J, Nei M and Kumar S (2007). MEGA4: Molecular evolutionary genetics analysis (MEGA) software version 4.0. Mol. Biol. Evol. 24: 1596-1599. http://dx.doi.org/10.1093/molbev/msm092

Unni E, Su S, Zraly CB and Mattox W (2003). Analysis of a null mutation in the Drosophila splicing regulator Tra2 suggests its function is restricted to sexual differentiation. Genesis 37: 76-83. http://dx.doi.org/10.1002/gene.10234

Ventura-Holman T and Maher JF (2000). Sequence, organization, and expression of the human FEM1B gene. Biochem. Biophys. Res. Commun. 267: 317-320. http://dx.doi.org/10.1006/bbrc.1999.1942

Ventura-Holman T, Seldin MF, Li W and Maher JF (1998). The murine fem1 gene family: homologs of the Caenorhabditis elegans sex-determination protein FEM-1. Genomics 54: 221-230. http://dx.doi.org/10.1006/geno.1998.5569

Ventura-Holman T, Lu D, Si X, Izevbigie EB, et al. (2003). The Fem1c genes: conserved members of the Fem1 gene family in vertebrates. Gene 314: 133-139. http://dx.doi.org/10.1016/S0378-1119(03)00712-1

Xiong WF, Shi JW, Jiang MY, Chen YL, et al. (2014). Structure characteristics of a masculinized fem-1c gene and its protein from Hyriopsis schlegelii. Acta Hydrobiol. Sin. 38: 1002-1007.

Zhang F, Chen L, Wu P, Zhao W, et al. (2010). cDNA cloning and expression of Ubc9 in the developing embryo and ovary of Oriental river prawn, Macrobrachium nipponense. Comp. Biochem. Physiol. B Biochem. Mol. Biol. 155: 288-293. http://dx.doi.org/10.1016/j.cbpb.2009.11.013

Zhang YP, Qiao H, Zhang WY, Sun SM, et al. (2013). Molecular cloning and expression analysis of two sex-lethal homolog genes during development in the oriental river prawn, Macrobrachium nipponense. Genet. Mol. Res. 12: 4698-4711. http://dx.doi.org/10.4238/2013.October.18.8

Zhang YP, Sun SM, Fu HT, Ge XP, et al. (2015). Characterization of the male-specific lethal 3 gene in the oriental river prawn, Macrobrachium nipponense. Genet. Mol. Res. 14: 3106-3120. http://dx.doi.org/10.4238/2015.April.10.21 